\title{
TINJAUAN KEBUTUHAN RAK PENYIMPANAN BERKAS REKAM MEDIS UNTUK 5 TAHUN KEDEPAN DI RUMAH SAKIT UMUM IMELDA PEKERJA INDONESIA MEDAN TAHUN 2018
}

\author{
${ }^{1 .}$ Siti Permata Sari Lubis; ${ }^{2 .}$ Junida Handayani \\ ${ }^{1 .}$ Dosen APIKES Imelda, Jalan Bilal Nomor 52 Medan; ${ }^{2 .}$ Alumni APIKES Imelda \\ E-mail: ${ }^{1 .}$ sitipermata29@yahoo.co.id
}

\begin{abstract}
ABSTRAK
Rak penyimpanan merupakan salah satu peralatan yang berada di rumah sakit yang berfungsi sebagai tempat untuk menyimpanan dokumen rekam medis, dengan tersedianya rak penyimpanan rekam medis yang sesuai dengan kapasitas penyimpanan dokumen rekam medis maka tidak akan terjadi penumpukan pada dokumen rekam medis. Maka dari itu peneliti bertujuan untuk mengetahui kebutuhan rak penyimpanan berkas rekam medis rawat jalan maupun rawat jalan untuk 5 tahun kedepan di Rumah Sakit Umum Imelda Pekerja Indonesia Tahun 2018. Jenis penelitian ini adalah deskriftif, metode yang digunakan dalam pengumpulan data antara lain dengan observasi langsung dan wawancara. Subjek dalam penelitian ini adalah rak penyimpanan dokumen rekam medis rawat jalan dan rawat inap, dan objek dalam penelitian ini adalah berkas rekam medis rawat jalan dan rawat inap.Berdasarkan hasil perhitungan tersebut dapat diketahui bahwa jumlah rak yang tersedia di RSU IPI Medan masih kekurangan rak untuk penyimpanan berkas rekam medis pasien baik rawat inap maupun rawat jalan.
\end{abstract}

Kata Kunci: Rak Penyimpanan, Berkas Rekam Medis, Kapasitas Rak.

\section{PENDAHULUAN}

Menurut PERMENKES 2008 yang dimaksud rekam medis adalah berkas yang berisikan catatan dan dokumen tentang identitas pasien, pemeriksaan, pengobatan, tindakan pelayanan lain yang telah diberikan kepada pasien. Rekam medis adalah siapa, apa, dimana dan bagaimana perawatan pasien selama dirumah sakit, untuk melengkapi rekam medis harus memiliki data yang cukup tertulis dalam rangkaian kagiatan guna menghasilkan suatu proses, jaminan, pengobatan dan hasil akhir.

Menurut PERMENKES 2008 tentang rekam medis pasal 8 yang menyebutkan bahwa rekam medis pasien di rumah sakit sekurang-kurangnya untuk jangka waktu 5 tahun terhitung dari hari terakhir pasien berobat atau dipulangkan.Berkas rekam medis yang lebih dari 5 tahun, akan disimpan di ruang penyimpanan medis rumah sakit dan lanjutan dengan penanganan berkas rekam medis yang meliputi penyelenggaraan penyimpanan untuk melayani permintaan atau peminjaman apabila dari pasien untuk keperluan dirinya. Penyimpanan berkas rekam medis yang memadai dan memenuhi standar akan mendukung pelayanan pasien yang maksimal.

PERMENKES 2008 pasal 7 menyebutkan bahwa sarana pelayanan kesehatan wajib menyediakan fasilitas yang diperlukan dalam rangka penyelenggaraan rekam medis. Rekam medis diselenggarakan oleh Unit Rekam Medis salah satunya yaitu filling yang merupakan media untuk penyimpanan dokumen rekam medis yang berfungsi sebagai penyimpan, penyedia dan pelindung dokumen rekam medis.

Berdasarkan survei pendahuluan yang dilakukan di Rumah Sakit Umum Imelda Pekerja Indonesia diketahui bahwa tempat 
penyimpanan rekam medis rawat jalan maupun rawat inap masih kurang. Hal tersebut bisa dilihat dari tabel 1.1 yang menunjukkan peningkatan jumlah pasien di RSU Imelda Medan.

Tabel 1. Jumlah Berkas Pasien Rawat Jalan dan Rawat Inap

\begin{tabular}{ccccc}
\hline TAHUN & Rawat Inap & Persen ( \% ) & Rawat Jalan & Persen ( \%) \\
\hline 2012 & 37400 & $21,83 \%$ & 30318 & $14,31 \%$ \\
\hline 2013 & 33670 & $19,65 \%$ & 41288 & $19,49 \%$ \\
\hline 2014 & 20113 & $11,74 \%$ & 38011 & $17,94 \%$ \\
\hline 2015 & 26081 & $15,22 \%$ & 39219 & $18,51 \%$ \\
\hline 2016 & 54000 & $31,53 \%$ & 63000 & $29,73 \%$ \\
\hline Total & $\mathbf{1 7 1 2 6 4}$ & $\mathbf{1 0 0 \%}$ & $\mathbf{2 1 1 8 3 6}$ & $\mathbf{1 0 0} \%$ \\
\hline
\end{tabular}

Berdasarkan tabel tersebut maka peneliti tertarik untuk melakukan penelitian dengan judul "Tinjauan Kebutuhan Rak Penyimpanan Berkas Rekam Medis Untuk 5 Tahun Ke Depan di Rumah Sakit Umum Imelda Pekerja Indonesia Medan Tahun $2017 "$.

\section{Rumusan Masalah}

Berdasarkan latar belakang masalah yang telah disebutkan diatas maka rumusan masalah dalam penelitian ini dirumuskan sebagai berikut : Masih ada berkas rekam medis pasien yang disimpan di kardus di ruang penyimpanan rekam medis RSU Imelda Pekerja Indonesia Medan.

\section{Tujuan Penelitian}

1. Menganalisis jumlah berkas rekam medis Rawat jalan dan rawat inap perhari.

2. Mengukur panjang dan lebar berkas rekam medis.

3. Menghitung jumlah rak penyimpanan rekam medis RSU Imelda Pekerja Indonesia Medan.

\section{Manfaat Penelitian}

1. Bagi rumah sakit untuk memberikan masukan dan bahan pertimbangan dalam pengambilan keputusan guna peningkatan mutu pelayanan kesehatan.

2. Bagi penulis agar dapat menerapkan teori yang penulis dapat dengan permasalahan yang penulis temukan sehingga dapat menambah wawasan berfikir dalam melaksanakan tugas rekam medis yang profesional.

3. Bagi lembaga pendidikan APIKES
Imelda Medanagar dapat digunakan sebagai bahan referensi untuk penelitian dan bahan pertimbangan bagi mahasiswa rekam medisatau bagi pihak lainnya.

\section{METODE}

\section{Jenis Penelitian}

Metode penelitian yang digunakan pada penelitian ini adalah metode deskriptif. Deskriptif adalah suatu penelitian yang dilakukan untuk mendeskripsikan atau menggambarkan suatu fenomena yang terjadi di dalam masyarakat (Notoatmodjo,2012). Jenis penelitian ini digunakan untuk mengetahui Tinjauan kebutuhan rak rekam medis untuk 5 tahun kedepan di RSU Imelda Pekerja Indonesia Medan.

\section{Waktu Penelitian}

Penelitian dilaksanakan pada bulan september 2017-januari 2018

\section{Tempat Penelitian}

Tempat yang dipilih menjadi penelitian adalah RSU Imelda Pekerja Indonesia.

\section{Subjek Penelitian}

Subjek penelitian dalam penelitian ini adalah rak penyimpanan berkas rekam medis di RSU Imelda Pekerja Indonesia

\section{Objek Penelitian}

Objek dalam penelitian ini adalah ruang penyimpanan berkas rekam medis. 


\section{Defenisi Operasional}

a. Rak penyimpanan rekam medis adalah tempat untuk menyimpan berkas rekam medis pasien agar tetap terjaga kerahasiaannya dan juga untuk mempermudah petugas untuk menyimpan dan mengambil berkas rekam medis.

b. Berkas rekam medis adalah berkas yang berisi catatan dan dokumen tentang identitas pasien, pemeriksaa, pengobatan, tindakan dan pelayanan lain yang diberikan pada pasien oleh sarana pelayanan kesehatan.

\section{Cara Pengumpulan Data}

1. Observasi

Pengamatan langsung terhadap kebijakan-kebijakan dan prosedur tetap sistem penyimpanan dan penjajaran di rumah sakit.

2. Pengukuran

Peneliti mengamati dan mengukur rak penyimpanan dokumen rekam medis rawat inap dan rawat jalan untuk mendapatkan ukuran panjang, lebar, tinggi, mengukur berkas, rak penyimpanan dokumen rekam medis.

3. Sumber data

Dalam penelitian ini adalah data yang berasal dari rak penyimpanan dokumen rekam medis rawat inap maupun rawat jalan.

\section{Teknik Analisi Data Penelitian}

Teknik analisis data yaitu dengan berpedoman pada jumlah kebutuhan rak penyimpanan dokumen rekam medis rawat inap maupun rawat jalan.

Instrumen penelitian yang digunakan dalam penulisan karya tulis ilmiah ini adalah:

1. Pedoman wawancara kepada kepala rekam medis dan staff unit rekam medis untuk mengetahui pasien baru perhari.

2. Menganalisis rak penyimpanan berkas rekam medis.

Instrumen:
1) Pulpen/pensil
2) Penggaris
3) Kertas
4) Vita sentimeter

\section{HASIL}

Berdasarkan penelitian yang dilakukan penulis mengenai “ Tinjauan Kebutuhan Rak Penyimpanan Berkas Rekam Medis Untuk 5 Tahun Kedepan Di RSU Imelda Pekerja Indonesia Medan Tahun 2018 “. Adalah masih kurangnya rak penyimpanan berkas rekam medis rawat jalan dan rawat inap.

\section{Jumlah Berkas Pasien Rawat Jalan dan Rawat Inap}

Dari tabel dibawah ini dapat diketahui bahwa jumlah pasien rawat jalan dan rawat inap dalam 5 tahun yang ada di RSU Imelda Pekerja Indonesia.

Tabel 2. Jumlah Berkas Pasien Rawat Jalan dan Rawat Inap

\begin{tabular}{ccccc}
\hline TAHUN & Rawat Inap & Persen ( \%) & Rawat Jalan & Persen ( \% ) \\
\hline 2012 & 37400 & $21,83 \%$ & 30318 & $14,31 \%$ \\
\hline 2013 & 33670 & $19,65 \%$ & 41288 & $19,49 \%$ \\
\hline 2014 & 20113 & $11,74 \%$ & 38011 & $17,94 \%$ \\
\hline 2015 & 26081 & $15,22 \%$ & 39219 & $18,51 \%$ \\
\hline 2016 & 54000 & $31,53 \%$ & 63000 & $29,73 \%$ \\
\hline Total & $\mathbf{1 7 1 2 6 4}$ & $\mathbf{1 0 0 \%}$ & $\mathbf{2 1 1 8 3 6}$ & $\mathbf{1 0 0} \%$ \\
\hline
\end{tabular}

\section{Ukuran Rekam Medis}

1. Rawat Jalan

Ukuran berkas rekam medis yang di RSU Imelda Pekerja Indonesia panjang $32 \mathrm{~cm}$,lebar 25 cmdantebal0,5 cm.

2. Rawat Inap
Ukuran berkas rekam medis yang di RSU Imelda Pekerja Indonesia panjang $32 \mathrm{~cm}$, lebar $25 \mathrm{~cm}$ dan tebal $1,5 \mathrm{~cm}$.

\section{Jumlah Sub Rak Rekam Medis}

Berdasarkan pengamatan (ovservasi) di tempat penyimpanan berkas rekam medis di 
RSUP Imelda Pekerja Indonesia mempunyai jumlah sub rak penyimpanan rekam medis yang disamakan tempat penyimpanan dengan berkas rekam medis rawat inap sebanyak 150 sub rak rekam medis.

\section{Jumlah Rak Penyimpanan Rekam Medis}

Jumlah rak yang berada diruang filling berkas rekam medis rekam medis rawat jalan dan rawat inap sebanyak 25 buah. Ada pun jarak untuk lalu lalang berjarak $50 \mathrm{~cm}$ sedangkan yang dianjurkan berjarak $90 \mathrm{~cm}$ untuk jarak lalu lalang.

Dengan jarak yang sedemikian, maka membuat petugas rekam medis kesulitan didalam melakukan kegiatan berupa pengambilan berkas rekam medis maupun penyimpan berkas rekam medis rawat jalan maupun rawat inap, di kerenakan tempat lalu lalang yang sempit.

\section{Jumlah Rekam Medis Di dalam Rak.}

Untuk menghitung berkas rekam medis didalam 1 sub rak penyimpanan rekam medis dibutuhkan, dari hasil pembahasan dapat diketahui bahwa ukuran rak penyimpanan berkas rekam medis terdiri dari 5 sub rak ke kesamping $100 \mathrm{~cm}$ dan 5 sub rak keatas dan bawah $30 \mathrm{~cm}$. Dengan ketebalan berkas rekam medis rata-rata 0,5 meter.

$=(5 \times(100 / 0,5) \times 5$

$=(5 \times 200) \times 5$

$=5000 \mathrm{RM}$ dalam $1 \mathrm{rak}$

Jadi jumlah berkas rekam medis dalam 1 rak sebanyak 5000 RM.

\section{PEMBAHASAN}

Penelitian ini untuk meninjau kebutuhan rak penyimpanan rekam medis rawat jalan dan rawat inap diRSU Imelda Pekerja Indonesia di dalam menghitung jumlah rak maupun luas penyimpanan rekam medis sebaiknya terlebih dahulu mengetahui jumlah rata-rata berkas rekam medis pasien baru rawat jalan perhari, jumlah berkas pasien rawat inap dan jumlah rekam medis yang aktif sehinga dapat mengetahui jumlah kebutuhan rak penyimpanan rekam medis rawat jalan dan rawat inap. Jumlah Berkas pasien rawat inap di RSU IPI Medan pada tahun 2012 sampai dengan 2016 adalah 171264 berkas dengan ukuran berkas panjang $32 \mathrm{~cm}$, lebar25 $\mathrm{cm}$ dan tebal $0,5 \mathrm{~cm}$, sedangkan jumlah berkas rekam medis yang rawat jalan adalah 211836 berkas dengan ukuran berkas panjang $32 \mathrm{~cm}$, lebar $25 \mathrm{~cm}$ dan tebal $1,5 \mathrm{~cm}$ di RSU Imelda Pekerja Indonesia.

Kebutuhan rak penyimpanan jumlah rekam medis rawat jalan yang aktif sebanyak 144.000 berkas rekam medis dalam 5 tahun dan jumlah kebutuhan rak untuk 5 tahun kedepannya sebanyak 34 rak.

1. Rata-rata jumlah berkas pertahunnya dilihat dari

Tabel 4.1Jumlah berkas rekam medis baru pada tahun 2016 sebanyak 54000 untuk rawat inap dan 63000 untuk rawat jalan.

2. Ukuran Rekam Medis

a) Rawat Jalan

Ukuran berkas rekam medis yang di RSU Imelda Pekerja Indonesia panjang $32 \mathrm{~cm}$, lebar $25 \mathrm{~cm}$ dan tebal $0,5 \mathrm{~cm}$.

b) Rawat Inap

Ukuran berkas rekam medis yang di RSU Imelda Pekerja Indonesia panjang $32 \mathrm{~cm}$, lebar $25 \mathrm{~cm}$ dan tebal $1,5 \mathrm{~cm}$.

3. Jumlah Sub Rak Rekam Medis

Hasil dari tinjauan di RSU Imelda Indonesia jumlah sub rak rekam medis sebanyak 150 sub rak rekam medis

4. Jumlah Rak Penyimpanan Rekam Medis

Jumlah sub rak penyimpanan berkas rekam medis diRSU Imelda Pekerja Indonesia sebanyak 25 rak.

Berdasarkan hasil perhitungan tersebut dapat diketahui bahwa jumlah rak yang tersedia di RSU IPI Medan adalah 25 rak dengan jumlah berkas rawat jalan 211836 berkas dan rawat inap 171264 berkas.

Jika 1 rak berisi 5000 berkas maka 25 rak berisi 125000 berkas, dari hal tersebut dapat di ketahui bahwa jumlah rak di RSU Imelda Pekerja Indonesia masih kekurangan rak untuk penyimpanan berkas rekam medis baik rawat inap maupun rawat jalan. 


\section{KESIMPULAN}

Dengan hasil penelitian mengggunakan metode observasi dan wawancara yang ada dibab IV dapat disimpulkan bahwa:

1. Berdasarkan hasil perhitungan tersebut dapat diketahui bahwa jumlah rak yang tersedia di RSU IPI Medan masih kekurangan rak untuk penyimpanan berkas rekam medis baik rawat inap maupun rawat jalan.

2. Jumlah rata-rata rekam medis baru pada tahun 2016 rawat inap sebanyak 54.000 dan rawat jalan 63.000 berkas rekam medis.

3. Ukuran rata-rata ketebalan dari berkas rekam medis untuk rawat inap panjang $32 \mathrm{~cm}$, lebar $25 \mathrm{~cm}$, dan ketebalan 0,5 $\mathrm{cm}$ untuk rawat jalan panjang $32 \mathrm{~cm}$, lebar $25 \mathrm{~cm}$ dan ketebalan $1,5 \mathrm{~cm}$.

\section{SARAN}

Berdasarkan kesimpulan diatas dapat disarankan untuk:

1. Bagi RSU Imelda Pekerja Indonesia, sebaiknya perlu penambahan berupa rak penyimpanan dokumen rekam medis rawat jalan maupun rawat inap yang terpisah untuk mempermudah petugas rekam medis melakukan kegiatannya di tempat penyimpanan tersebut.

2. Bagi pendidikan Rekam Medis, agar lebih mengetahui bagaimana cara menghitung kebutuhan rak penyimpanan di ruang penyimpanan berkas rekam medis.

3. Bagi Instalasi Rekam Medis, agar melakukan penambahan rak penyimpanan berkas rekam medis yang terpisah antara rawat jalan dan rawat inap.

4. Bagi peneliti selanjutnya, agar melakukan penelitian di rumah sakit lain sehingga memenerapkan pengalaman dan pengetahuan pada hasil penelitian yang pernah dilakukan.

\section{DAFTAR PUSTAKA}

Ahmadi. (2011). Tinjauan Kebutuha Nrak Penyimpanan Rekam Medis Rawat Jalan Di RSU Dr. H. Moch. Ansari Saleh Banjarmasin. KTI STIKES HUSADAH. BORNEO.

Depkes RI Dirjen Yanmed. (2006). Pedoman Pengelolaan Rekam Medis Rumah Sakit di Indonesia. Jakarta: DepKes.

Hatta, Gemala R. (2010). Pedoman Pengelolaan Rekam Medis Rumah Sakit di Indonesia. Jakarta: Direktor Jendral Pelayanan Medik Depkes RI.

Irfan. (2009). Prediksi Kebutuhan Rak Penyimpanan Dokumen Rekam Medis Aktif Di Bagian Filing Rumah Sakit Umum Daerah Kabupaten Sragen. Jurnal Kesehatan, ISSN 1979-955), VOL III, No. 20, Oktober 2009, Hal 80101.

Notoatmodjo S. (2012). Metodologi Penelitian Kesehatan. Jakarta: Rineka Cipta.

Permenkes RI No.269/MENKES/PER/III/2008.

Tentang Rekam Medis. Jakarta.

Rustiyanto E. (2009). Etika Profesi. Yogyakarta: Graha Ilmu. 